\title{
The nucleus accumbens and alcoholism: a target for deep brain stimulation
}

\author{
Allen L. Ho, MD, ${ }^{1}$ Anne-Mary N. Salib, BS, ${ }^{1,2}$ Arjun V. Pendharkar, MD,, Eric S. Sussman, MD, ${ }^{1}$ \\ William J. Giardino, PhD, ${ }^{2}$ and Casey H. Halpern, MD ${ }^{1,2}$ \\ Departments of ${ }^{1}$ Neurosurgery and ${ }^{2}$ Psychiatry and Behavioral Sciences, Stanford University School of Medicine, Stanford, \\ California
}

\begin{abstract}
Alcohol use disorder (AUD) is a difficult to treat condition with a significant global public health and cost burden. The nucleus accumbens (NAc) has been implicated in AUD and identified as an ideal target for deep brain stimulation (DBS). There are promising preclinical animal studies of DBS for alcohol consumption as well as some initial human clinical studies that have shown some promise at reducing alcohol-related cravings and, in some instances, achieving long-term abstinence. In this review, the authors discuss the evidence and concepts supporting the role of the NAc in AUD, summarize the findings from published NAc DBS studies in animal models and humans, and consider the challenges and propose future directions for neuromodulation of the NAc for the treatment of AUD.

https://thejns.org/doi/abs/10.3171/2018.5.FOCUS18157
\end{abstract}

KEYWORDS nucleus accumbens; alcoholism; binge drinking; deep brain stimulation; responsive neurostimulation; neuromodulation; addiction

$\mathrm{D}$ EEP brain stimulation (DBS) has been successfully used for the treatment of movement disorders for more than 2 decades. More recently, DBS has been applied toward the treatment of a wide variety of neuropsychiatric disorders. Given the significant disease and economic burden of disorders of addiction, DBS has been proposed as a therapeutic strategy for treatment-refractory individuals. ${ }^{18}$ This is especially relevant for alcohol use disorder (AUD), in which current medical therapies and intensive treatment programs suffer from high rates of noncompliance, variable effectiveness, and serious side effects. Indeed, up to $75 \%$ of treated alcoholics relapse within 3 years. ${ }^{64}$ The nucleus accumbens (NAc) plays a central role in the mesolimbic reward pathway, and has been the most well-studied target for neuromodulatory therapies for AUD ${ }^{36}$ In this review, we will discuss the evidence and concepts supporting the role of the NAc in AUD, summarize the findings from published NAc DBS studies in animal models and humans, and consider the challenges and propose future directions for neuromodulation of the NAc for the treatment of AUD.
Alcohol use disorder affects more than 76 million people worldwide ${ }^{51}$ and is classified by the Diagnostic and Statistical Manual of Mental Disorders (DSM-V) into 3 distinct gradations: mild, moderate, and severe, with each correlating to increasing degrees of addiction or dependency. ${ }^{1}$ However, as a drug of abuse alcohol is unique in that binge consumption of large quantities of alcohol beyond what is necessary to achieve normal intoxication is exhibited at all levels of AUD, and is the preferred method of consumption for those with the most severe AUD. In the US, binge drinking is how most young Americans are introduced to alcohol, and is responsible for $90 \%$ of the alcohol consumed by individuals under the age of 21 years. ${ }^{48}$ Indeed, $70 \%$ of the binge drinking in the US occurs in people who are younger than 26 years, ${ }^{26}$ and this behavior in early adulthood is highly predictive of alcohol dependence. ${ }^{43}$ The economic burden of alcohol misuse in the US is estimated at $\$ 250$ billion dollars or more than $2 \%$ of gross domestic product (GDP), and three-quarters of this is directly related to binge-drinking behavior. ${ }^{57}$

Conceptually, AUD can be defined as a disorder that

ABBREVIATIONS AUD = alcohol use disorder; $A \cup Q=$ Alcohol Urge Questionnaire; $B O L D=$ blood oxygen level-dependent; $D B S=$ deep brain stimulation; fMRI = functional MRI; GABA $=\gamma$-aminobutyric acid; $\mathrm{mPFC}=$ medial prefrontal cortex; NAc $=$ nucleus accumbens; VTA $=$ ventral tegmental area.

SUBMITTED April 1, 2018. ACCEPTED May 14, 2018.

INCLUDE WHEN CITING DOI: 10.3171/2018.5.FOCUS18157. 
includes a progression from impulsivity driven by positive reinforcement in the initial states of AUD to compulsivity driven by negative reinforcement in severe AUD (Fig. 1). Negative reinforcement is defined as drug taking to relieve a negative emotional state that is derived from dysregulation of reward and stress response circuitry within basal forebrain structures including the NAc and amygdala. These pathological states are further compounded by physiological and mental withdrawal symptoms experienced by those with severe AUD. ${ }^{37}$

\section{Nucleus Accumbens and Alcohol}

It was first suggested in the 1970s that drug addiction was intimately related to dysregulation of the neural reward circuitry, ${ }^{4}$ and since that time all drugs of abuse, including alcohol, have been demonstrated to increase dopamine levels in the brain-with the most pronounced effect occurring in the NAc, which is the primary target of the mesolimbic dopamine system and the center of the brain's reward system. ${ }^{42}$ There is a robust body of evidence supporting the effect of alcohol on the NAc. In murine models, increases in serum ethanol levels via direct injection have been demonstrated to increase extracellular dopamine levels measured by in vivo microdialysis and voltammetry. ${ }^{29}$ Similarly, voluntary consumption of ethanol increases accumbal dopamine levels and restores deficits in dopamine seen in withdrawal states in ethanol-dependent rats. ${ }^{44}$ Dopamine levels in the NAc also increase in anticipation of ethanol availability, implicating the NAc in the alcohol relapse process. ${ }^{41}$ Conversely, in multiple rodent studies, blockades of dopamine receptors within the NAc have successfully reduced ethanol consumption, ${ }^{9}$ an effect that may be mediated via a D2 receptor mechanism. ${ }^{50}$ Furthermore, lesioning of dopaminergic neurons or dopamine targets within the NAc increases ethanol consumption. ${ }^{21,52}$ More specifically, it has recently been demonstrated that the functionally and anatomically distinct subregions of the NAc-the core and the shell-are involved in alcohol-seeking behavior. Pharmacological inactivation of the NAc core reduced conditioned responses to discrete alcohol cues, implicating the NAc core in cueinduced relapse behavior. Conversely, pharmacological inactivation of the of the NAc shell reduced conditioned responses to alcohol contexts, implicating the NAc shell in context-induced relapse behavior. ${ }^{6}$

On a cellular level, $\gamma$-aminobutyric acidergic (GABAergic) medium spiny neurons make up the majority of the neurons of the NAc. They receive extensive glutamatergic inputs from limbic areas such as the medial prefrontal
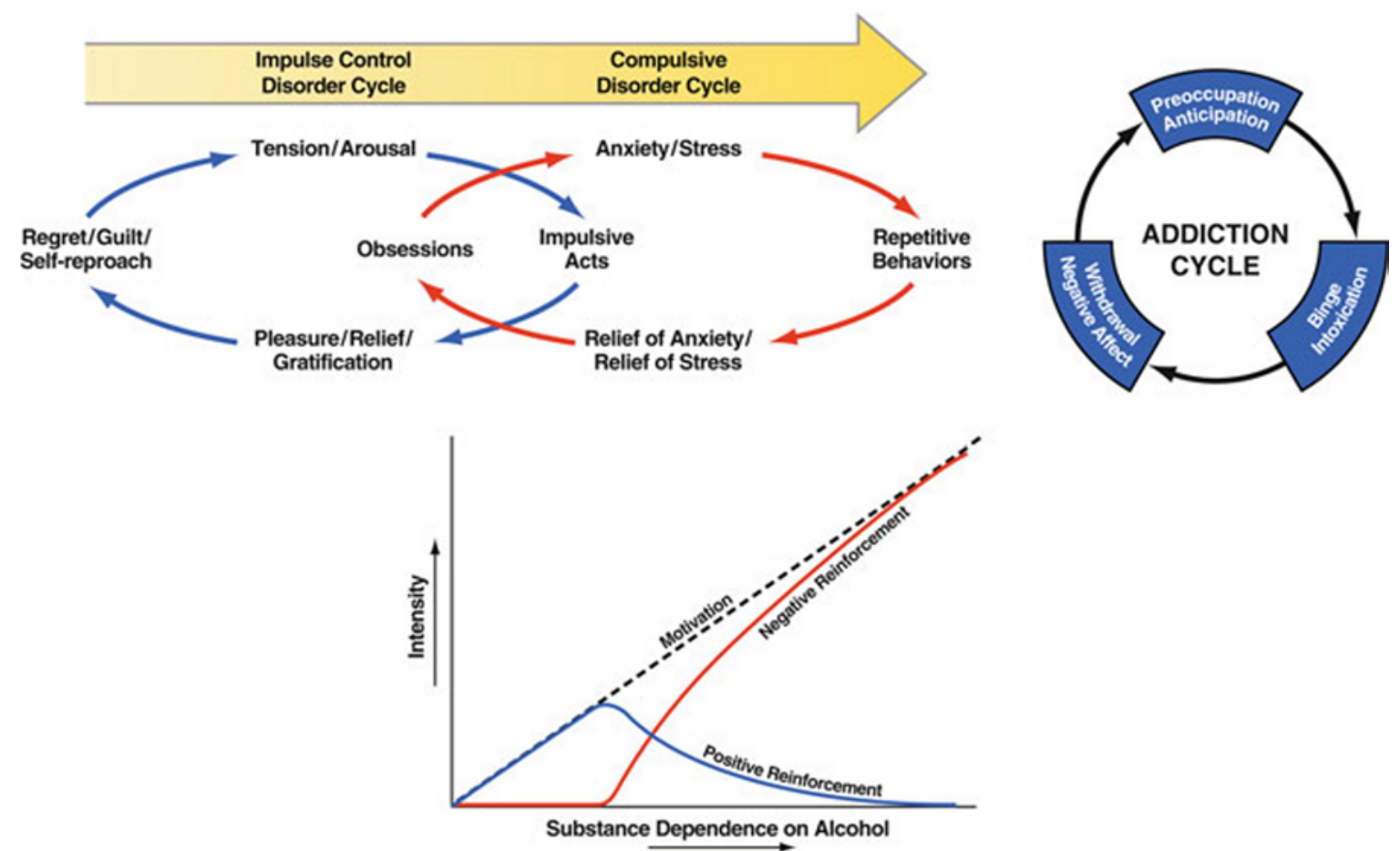

FIG. 1. Impulse-control disorder and compulsive disorder cycles in patients with AUD. Upper left: Within the initial impulse-control disorder cycle, tension and arousal occur before the impulsive act, with pleasure, gratification, or relief experienced during the act, followed by regret or guilt. In compulsive disorders, obsessions (recurrent and persistent thoughts) cause marked anxiety and stress, followed by compulsions (repetitive behaviors) that are aimed at preventing or reducing distress. Positive reinforcement is associated with impulse-control disorders, and negative reinforcement is closely associated with compulsive disorders. Upper right: The addiction cycle can be conceptualized as consisting of 3 major components: preoccupation/anticipation, binge/intoxication, and withdrawal/negative affect. Lower: Change in the relative contribution of positive and negative reinforcement constructs during the development of dependence on alcohol. ${ }^{37}$ Reprinted by permission from Springer Nature: Springer. Curr Top Behav Neurosci. Theoretical frameworks and mechanistic aspects of alcohol addiction: alcohol addiction as a reward deficit disorder. Koob GF. @ 2013. 
cortex (mPFC), hippocampus, and basolateral amygdala, and they project widely to the ventral pallidum, substantia nigra, and ventral tegmental area (VTA), as well as forming interconnections within the NAc. ${ }^{63,71}$ Medium spiny neuron plasticity has been shown to be critical in addictive states, ${ }^{15}$ and several studies have also supported the central role of medium spiny neurons in mediating the reinforcing properties of alcohol. ${ }^{49,54}$ Recently, it has been revealed that $\mathrm{mPFC}$ projections to the medium spiny neurons of the NAc are critical for paired alcohol-cue associations and that ablation of these projections decreases the cue-induced reinstatement of previously conditioned alcohol-consumption behavior. ${ }^{33}$ Finally, the role of the VTA-dependent dopamine release from terminal fields within the NAc in ethanol-drinking behaviors has also been elucidated. Activity of these VTA-NAc projections correlate with degree of ethanol consumption, and optogenetic stimulation of the VTA and specific VTA-NAc projections induced tonic increases in NAc dopamineattenuated ethanol-drinking behavior in rodent models..$^{2,31}$

In humans, advances in neuroimaging have allowed neurochemical and functional studies of alcohol consumption that have also implicated the NAc. Alcohol consumption in human studies has enhanced extracellular dopamine levels in the NAc, and these effects were correlated with subjective feelings of euphoria and stimulation. ${ }^{53,65}$ Significant derangements of the dopamine system have been seen in abstinent alcoholics, in whom studies have demonstrated reduced dopamine synthesis, decreased numbers of D2/3 receptors, and reduced binding to these receptors after dopamine reuptake inhibitor challenges (methylphenidate or amphetamine) compared to normal controls. ${ }^{22}$ The opposite effects are seen in alcohol craving states or in subsequent relapse states. Similarly, in functional blood oxygen level-dependent (BOLD)-MRI studies of heavy consumers of alcohol there is increased BOLD activation within mesolimbic circuitry, including the NAc, in response to alcohol cues compared to results in light consumers. This cue-induced activity within the NAc was strongly correlated with length of alcohol use. ${ }^{7,28}$ In fact, in a meta-analysis of all alcohol cue-induced functional imaging studies, NAc activation correlated most strongly with degree of AUD and with AUD treatment response. ${ }^{58}$ Taken together, the data from animal and human studies strongly support the notion that it is a reduced baseline dopamine activity within the NAc and concomitant hyperactivity in response to alcohol cues and contexts that increasingly drives alcohol consumption in the progression of AUD.

\section{Nucleus Accumbens DBS}

The history of neurosurgical treatment of AUD begins with ablative therapies. The first large series of alcohol-addicted patients treated with bilateral stereotactic cingulotomy, reported by Kanaka and Balasubramaniam in 1978, demonstrated complete abstinence in $68 \%$ of patients. ${ }^{32}$ However, there have since been neurocognitive side effects (including impaired focused attention and other executive impairments) reported from this procedure. ${ }^{73}$ Based on evidence in humans and animals that blocking the NAc response to drugs and drug-related cues may decrease cravings and relapse rates, more recent ablative therapies have focused on the NAc. A group from China published a study of 28 drug-addicted patients who underwent bilateral ablation of the NAc core, with a mean follow-up of 15 months. Complete remission was achieved in 7 patients, and 10 patients relapsed within 6 months but with less severe symptoms. ${ }^{12}$ Long-term follow-up and expansion of this treatment cohort revealed a $47.4 \%$ total 5 -year abstinence rate in the 60 individuals who completed the therapy. Several psychological indices were also improved in those who remained abstinent. ${ }^{13}$

Although the exact mechanism of high-frequency DBS has not been elucidated, there are several hypotheses that question whether target inhibition-in a manner similar to an ablative lesionectomy-may occur via 1) a depolarization blockade, ${ }^{3}$ 2) GABA-mediated synaptic inhibition, ${ }^{10}$ or 3) stimulation-mediated synaptic depletion. ${ }^{66}$ Other theories suggest that DBS desynchronizes pathological neuronal network activity. ${ }^{20}$ Whatever the exact mechanism of action, the rationale of applying DBS toward the NAc in the treatment of AUD is based on its role in the processing of rewards and cognitive control in the face of cue-induced cravings, and the efficacy of this therapy has been studied in both animal models and in human subjects (Fig. 2).

\section{Animal Investigations}

Details of all published animal studies of NAc DBS for AUD can be found in Table 1. The first animal study of DBS in AUD was published in 2009 by Knapp et al.

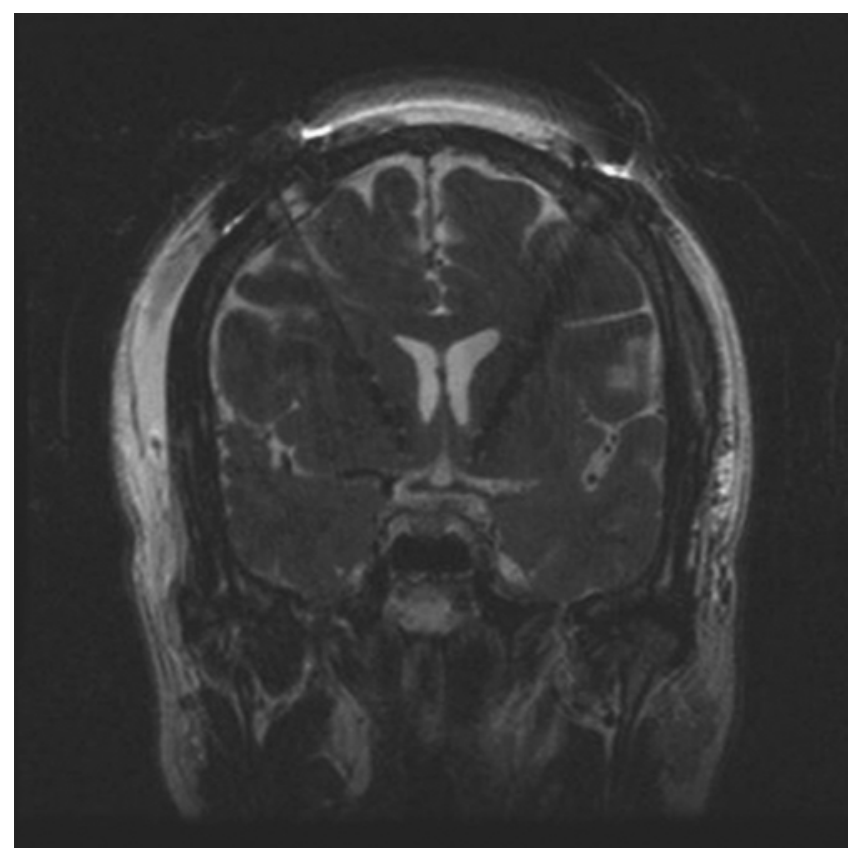

FIG. 2. NAc DBS. A T2-weighted MRI scan in the coronal view representing bilateral implantations of DBS leads in the ventral capsule/ ventral striatum in the region of the NAc. ${ }^{18}$ Reprinted by permission from Springer Nature: Springer-Verlag GmbH Austria. Acta Neurochir (Wien). Expanding applications of deep brain stimulation: a potential therapeutic role in obesity and addiction management. Halpern et al. (c) 2011. 


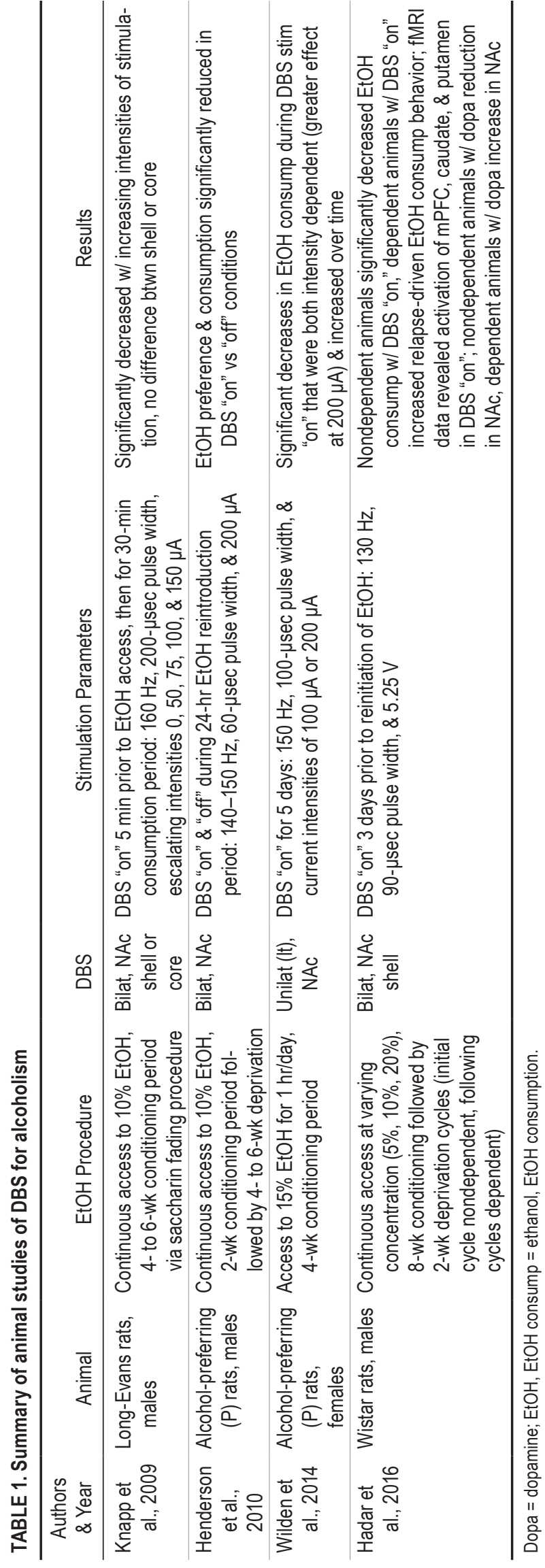

In that study, Long-Evans rats were given access to $10 \%$ ethanol with water until intake stabilized. Bilateral DBS leads were then implanted in either the shell or the core of the NAc, and DBS was delivered for 5 minutes prior to ethanol access and then continued for 30 minutes, during which the volume of consumption was measured. Ethanol consumption was significantly reduced with increasing intensities of DBS, but there was no significant difference in consumption between those rats receiving NAc core or shell DBS. ${ }^{35}$

In 2010, a second study by Henderson et al. used alcohol-preferring rats that were selectively bred to spontaneously binge ethanol in large quantities and, similar to humans, have also been shown to also increase intake after a period of deprivation. These animals underwent placement of bilateral NAc DBS, and both alcohol preference and consumption were significantly reduced in DBS "on" conditions versus sham stimulation "off" conditions. ${ }^{25}$

In 2014 another study was conducted in female alcoholpreferring rats in which animals were implanted with a unilateral (left) DBS, then resumed on a drinking protocol of 1 hour a day of $15 \%$ ethanol. Subsequently, DBS was administered during ethanol exposure times for 5 days, and significant decreases were seen in ethanol consumption during the stimulation periods that were both stimulation intensity-dependent (greater effect at $200 \mu \mathrm{A}$ ) and increased over time (drop in ethanol consumption was greater with each successive day).$^{68}$

Finally, a more recent study sought to examine the effects of NAc DBS on gating relapse-like drinking behavior in a male Wistar rat model that combined stimulation with functional MRI (fMRI) and neurotransmitter (dopamine) data. Rats were given continuous access to varying concentrations of ethanol for 8 weeks prior to a 2 -week deprivation period before experimental ethanol exposure was instituted. Following the first deprivation period animals were considered nondependent on ethanol, and on successive repetitions of the protocol were considered ethanol dependent. Chronic continuous DBS was initiated during each deprivation period 3 days prior to reinstatement of ethanol. The fMRI data obtained during this period revealed activation of the mPFC, caudate, and putamen. Although initial stimulation in nondependent animals significantly decreased ethanol consumption, subsequent cycles of stimulation in so-called dependent animals actually increased relapse-driven ethanol-consumption behavior. A similar trend was seen with dopamine activity following DBS. ${ }^{16}$

\section{Human Studies}

In humans, the impact of NAc stimulation on alcohol consumption has only been reported in a handful of patients. The details of these studies are listed in Table 2 . The first was a case report by Kuhn et al. published in 2007 that detailed the course of a 54-year-old man with severe anxiety, secondary depressive disorder, and severe alcohol dependency with daily alcohol consumption of more than 10 drinks/day and previous hospitalizations for withdrawal. NAc DBS was offered as a pilot intervention due to the severity of the symptoms and the refractory nature of the psychiatric disorder in this individual, the past 


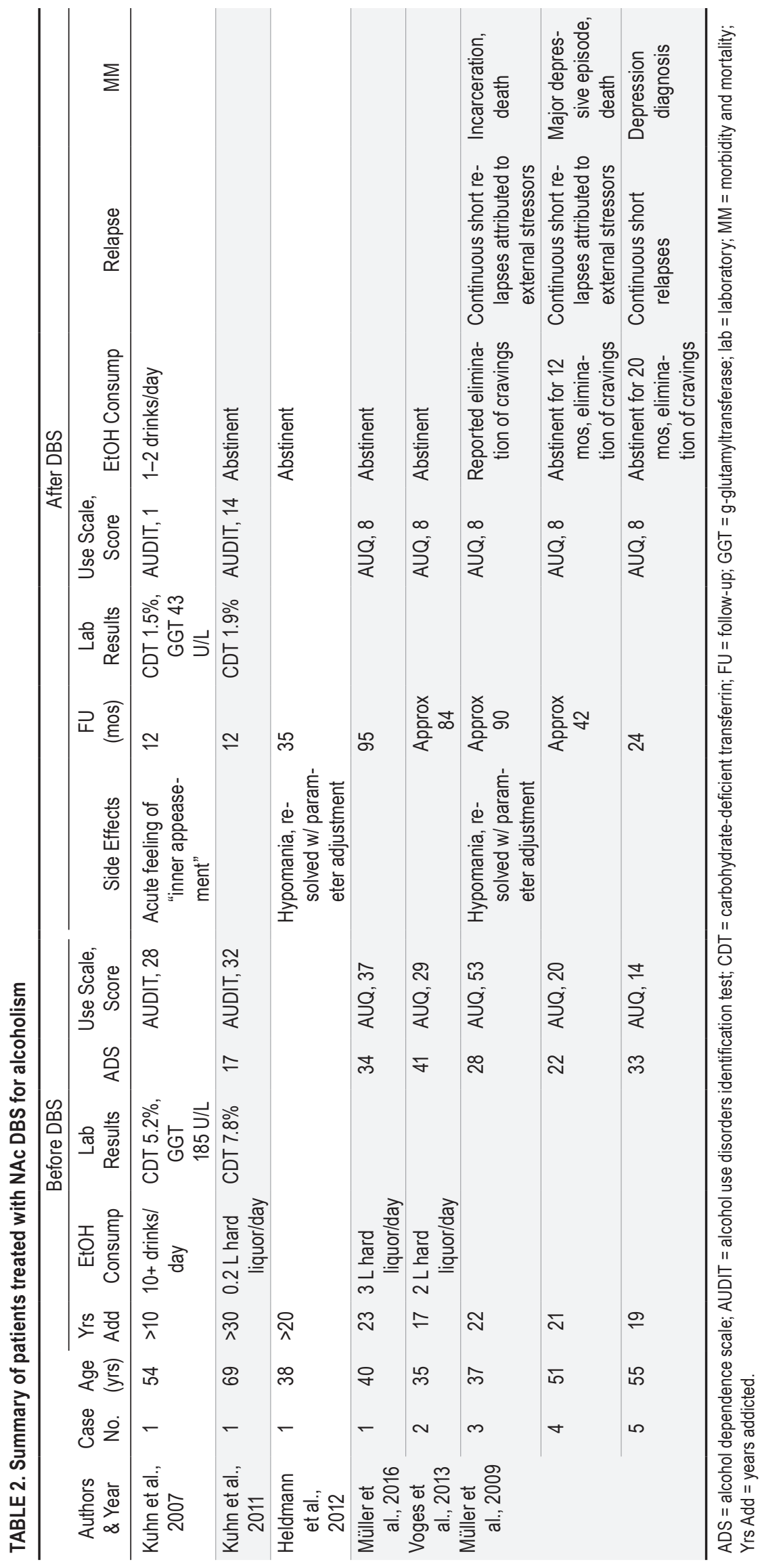


efficacy of DBS in treating obsessive-compulsive disorder and anxiety, and the reciprocal interest of the patient. ${ }^{62}$ $\mathrm{He}$ received bilateral NAc DBS, and optimal settings that minimized adverse reactions were reached after an initial programming period of several weeks. There was no change in the severity of the patient's anxiety or depression. However, following initiation of DBS, the patient rapidly and drastically reduced his alcohol consumption, and within 1 month was consuming 1-2 drinks/day and subjectively reported having completely lost the desire to drink. ${ }^{40}$ This same group treated another patient in 2011: a 69-year-old man with a more than 30-year history of alcohol dependence, consuming more than $200 \mathrm{~g}$ of vodka daily. $\mathrm{He}$ also received numerous detoxifications, withdrawal treatments, and psychopharmacological interventions that had all failed. Similar to the first patient, after receiving bilateral NAc DBS, the patient began to remarkably reduce his alcohol consumption and was completely abstinent after 1 year. ${ }^{39}$

Because of published reports such as the Kuhn et al. 2007 study, a small clinical trial was initiated with the goal of enrolling multiple patients for NAc DBS for the treatment of severe alcoholism..$^{23,47} \mathrm{~A}$ total of 5 patients included in this study were considered severely addicted to alcohol and on average consumed at least $200 \mathrm{~g}$ of ethanol per day for more than 10 years, and previous detoxifications, inpatient programs of at least 6 months, and pharmaceutical interventions (acamprosate and/or naltrexone) had all failed. ${ }^{23,46,67}$ After receiving bilateral NAc DBS, the patient in case 1 became completely abstinent without any cravings or psychological side effects, and remained abstinent 8 years after initiation of treatment. The patient in case 2 experienced a marked reduction in alcohol-related cues and cravings, and on the last long-term follow-up evaluation had been abstinent for 6 years since initiation of treatment. The patient in case 3 had both a significant drinking as well as an incarceration history, but also enjoyed a 1-year period of abstinence following initiation of NAc DBS therapy. However, he then experienced several short periods of relapse, although he reported significant reduction in alcohol-related cravings, and instead attributed his relapses to significant external life stressors. Unfortunately, 3 years after implantation he was incarcerated for 4 years, and his alcohol cravings resurfaced after his battery ran out of power while he was incarcerated. The patient died soon after of unknown causes. The patient in case 4 also enjoyed an initial abstinent period of 1 year, but then he had several short-term relapses attributed to external stressors. He developed major depressive disorder at 3 years that was treated into remission. However, he continued to relapse into the 4th year, claiming that the alcohol helped him cope with the tragic death of his brother, and he was eventually lost to follow-up. He was found dead in his home some time later of unknown causes. The patient in case 5 had nearly 20 months of abstinence before the first of several short relapses every $2-3$ months. He also reported a disappearance of cravings but the continued presence of external life stressors that drove his relapses. He developed depressive symptoms 24 months after treatment that were also treated with antidepressant medication and psychotherapy.
All patients in this trial reported resolution of alcohol cravings including cue-induced cravings in everyday life, consistent with their Alcohol Urge Questionnaire (AUQ) results post-DBS. Despite a reduction in their declared urge, several patients were unable to remain completely abstinent, leaving room for the possibility that consumption of alcohol essentially shifted from goal-directed behavior to habitual behavior. The absence of craving for alcohol is consistent with the hypothesis that DBS of the NAc may be modulating the reward system of the brain, which was otherwise modulated maladaptively by alcohol. ${ }^{11,30}$ Two of the 5 patients died, with implications that continuous alcohol consumption contributed to their deaths. However, it is difficult to identify with certainty what was the cause of death in these patients. ${ }^{23,24,46}$

\section{Challenges and Future Directions Modeling of AUD}

Given the complexity of AUD, animal models are crude in comparison to the full spectrum of human AUD, and no single animal model can represent all the various combinations and complexities embodied in human alcoholism. However, across multiple partial paradigms it is possible to capture hallmarks of analogous physiology and behaviors. Long-term continuous access ${ }^{35}$ coupled with a period of deprivation to produce an alcohol deprivation effect ${ }^{61}$ may better mirror the long-term consequences of alcoholism and be a better vehicle with which to study the relapse and withdrawal aspects of the chronic disease, ${ }^{25}$ whereas more short-term, intermittent exposure may better provoke binge patterns of heavy drinking that can reliably achieve human levels of intoxication with blood ethanol concentrations of greater than $0.08 \%(80 \mathrm{mg} / \mathrm{dl}){ }^{48}$ Contrasting the positive reinforcement drivers of impulsivity with the negative reinforcement drivers (i.e., withdrawal, negative emotional states) of the compulsion that develops with long-term alcoholism, binge consumption behavior in both stages is motivated by different factors and does not represent the same underlying neurological pathology. ${ }^{38}$ Heightened reward sensitivity related to loss of top-down control from the PFC and dysregulation of mesolimbic circuitry leads to impulsivity and is the primary and most specific behavioral pathology targeted in NAc stimulation. ${ }^{14,34}$ This picture is complicated once long-term dependence and withdrawal states are invoked, because binge behavior becomes driven not only by impulsivity that is primarily controlled by the NAc, but also under the influence of negative emotional states and limbic system deregulation. ${ }^{69}$ Targeting of the specific impulse-driven binge behavior has been effective in ameliorating consummatory behaviors such as binge eating. ${ }^{17}$ Future studies of NAc DBS should be clear regarding the specific component of AUD being modeled and should be geared toward more reliable models of impulsivity-driven binge-drinking behaviors. ${ }^{56,59}$

\section{Mechanism of NAc DBS}

Although numerous studies demonstrate a reliable treatment effect of NAc DBS on binge alcohol-drinking behaviors in animal models, a clear delineation of possible underlying mechanisms of NAc DBS remains elusive 
and warrants closer study. For example, in binge eating, Halpern et al. found that D2 receptor antagonists reversed the modulatory effects of DBS in a mouse model of binge eating, suggesting that dopamine signaling specific to D2 receptors played a crucial role in the effect of NAc DBS. ${ }^{17}$ This is congruent with initial findings that D2 receptordeficient mice had a marked aversion to ethanol compared to wild-type littermates and that there was no change in this phenotype with administration of D1 receptor antagonists. ${ }^{50}$ Similar mechanistic studies need to be undertaken in the context of NAc DBS in models of binge ethanol consumption. As avenues for molecular and electrochemical inquiry continue to progress, more targeted and robust techniques should be considered. For example, reverse pharmacogenetic inactivation of NAc-specific neuronal firing with Designer Receptors Exclusively Activated by Designer Drugs (DREADDs) was able to suppress alcohol consumption in a "Drinking in the Dark" (DID) binge-drinking mouse model..$^{5}$ Another recent study used retrograde tracing, electrophysiology, optogenetics, and behavioral assays to identify region-specific subpopulations within the NAc shell that exert differential effects. Neurons in the medial shell subdivision of the NAc were revealed to exert direct inhibitory control over mesolimbic dopamine neurons within the VTA via activation of GABA receptor subtypes, whereas lateral shell neurons mainly synapsed onto VTA GABA neurons that participated in a feedback loop to the NAc..$^{72}$ Coupling these new mechanistic experimental paradigms with NAc DBS and robust behavioral binge-drinking models will be critical for discovery of the underlying mechanism by which NAc stimulation may exert its effects.

\section{Clinical Considerations}

It is clear from the small sample size of the cases reviewed above that, although NAc DBS for the treatment of alcoholism may have some powerful effects in terms of alcohol craving and consumption reduction, this is an inherently difficult patient population that is prone to morbidity and mortality. Although craving-induced ethanol consumption may be effectively targeted with this surgical approach, there appear to be few positive ancillary effects on comorbid psychiatric conditions such as anxiety and depression, ${ }^{40,46}$ and external psychosocial stressors, such as incarceration or a death in the family, can lead to alcohol relapse despite lack of cravings. Although they were probably multifactorial in etiology, the two unexplained deaths from the single completed trial of NAc DBS for alcoholism underscores the overall limitations in improving the general well-being of these patients despite successful targeted intervention for reducing alcohol consumption. ${ }^{46}$ A similar experience was seen in a recent study for NAc DBS for morbid, treatment-refractory obesity, in which 3 patients received implants -1 of whom withdrew from the study and ultimately had the leads explanted; 1 patient committed suicide; and 1 patient successfully completed the 3-year study, with an impressive BMI reduction from 55.7 to $39.3 \mathrm{~kg} / \mathrm{m}^{2}$. The study authors also concluded that it was the psychiatric comorbidities and exposure to significant psychosocial stressors that led to the poor outcomes. ${ }^{55}$ These parallel lessons from previous studies of binge be- havior should be well taken for future trials of this interventional paradigm. Attention should be paid not only to the adoption of stringent inclusion and exclusion criteria for enrollment, but a protocol should be established for mitigation of and building a support system for the inevitable psychosocial stressors encountered in this difficult patient population with medically refractory consumptionrelated addictions.

Finally, previous studies have all adopted conventional continuous "open-loop" DBS paradigms that have been successful in the treatment of movement disorders. Recent success with responsive neurostimulation systems in the treatment of epilepsy has demonstrated the effectiveness of "closed-loop" recording and intermittent stimulation systems for the treatment of episodic electrical pathology within the brain. ${ }^{45}$ Consumption-driven disorders of impulsivity may be ideal for this type of closed-loop treatment if stimulation could be delivered during brief windows of anticipation, or so-called moments of weakness prior to the initiation of a binge. ${ }^{8,60} \mathrm{Wu}$ et al. recently published a translational study validating this technique. They were able to identify a conserved local-field-potential biomarker of delta (1-4 Hz) oscillations from NAc recordings in mice prior to a food binge and in humans during a monetary incentive delay task. This local-field-potential biomarker was then used in a closed-loop responsive neurostimulator system to effectively ameliorate binge-eating behavior in mice with only targeted stimulation delivered at times of binge anticipation. ${ }^{70}$ If analogous electrographic biomarkers of reward anticipation can be identified in binge drinking, a similar closed-loop approach may be effective for the treatment of alcoholism via the NAc and may help minimize any potential stimulation-related side effects. Indeed, a study that coupled cue-reactive fMRI BOLD signal data with resting-state electroencephalographic recording demonstrated that increased beta activity in the anterior cingulate cortex and gamma activity in the anterior cingulate cortex, ventromedial PFC, and orbitofrontal cortex revealed a hyperconnected central craving network that was disrupted with introduction of alcohol cues. Cue reactivity was correlated with increased fMRI BOLD activity in the amygdala, parahippocampal gyrus, NAc, and striatum. ${ }^{27}$ This finding of coordinated neural and metabolic activity in response to alcohol stimulus would support the notion that a similar anticipatory signature may be present within the NAc and could be used as a trigger for stimulation.

\section{Conclusions}

Alcohol use disorder is a difficult to treat condition with a significant global public health and cost burden. The NAc has been implicated in AUD and identified as an ideal target for DBS. Although some initial clinical studies have shown some promise at reducing alcohol-related cravings and, in some instances, achieving long-term abstinence, patients with AUD are an inherently difficult patient population to manage. Continuing studies are necessary to establish efficacy, with a focus on mitigation of outside psychosocial stressors encountered during treatment periods. Future efforts may also clarify the underlying molecular 
and electrophysiological mechanisms of NAc stimulation in AUD, and leverage newer responsive technologies to further refine and improve neuromodulatory treatments.

\section{References}

1. American Psychiatric Association: Diagnostic and Statistical Manual of Mental Disorders (DSM-V). Arlington, VA: American Psychiatric Association, 2013

2. Bass CE, Grinevich VP, Gioia D, Day-Brown JD, Bonin KD, Stuber GD, et al: Optogenetic stimulation of VTA dopamine neurons reveals that tonic but not phasic patterns of dopamine transmission reduce ethanol self-administration. Front Behav Neurosci 7:173, 2013

3. Beurrier C, Bioulac B, Audin J, Hammond C: High-frequency stimulation produces a transient blockade of voltage-gated currents in subthalamic neurons. J Neurophysiol 85:13511356,2001

4. Carlsson A, Engel J, Svensson TH: Inhibition of ethanolinduced excitation in mice and rats by -methyl-p-tyrosine. Psychopharmacology (Berl) 26:307-312, 1972

5. Cassataro D, Bergfeldt D, Malekian C, Van Snellenberg JX, Thanos PK, Fishell G, et al: Reverse pharmacogenetic modulation of the nucleus accumbens reduces ethanol consumption in a limited access paradigm. Neuropsychopharmacology 39:283-290, 2014

6. Chaudhri N, Sahuque LL, Schairer WW, Janak PH: Separable roles of the nucleus accumbens core and shell in contextand cue-induced alcohol-seeking. Neuropsychopharmacology 35:783-791, 2010

7. Claus ED, Ewing SWF, Filbey FM, Sabbineni A, Hutchison KE: Identifying neurobiological phenotypes associated with alcohol use disorder severity. Neuropsychopharmacology 36:2086-2096, 2011

8. Crockett MJ, Braams BR, Clark L, Tobler PN, Robbins TW, Kalenscher T: Restricting temptations: neural mechanisms of precommitment. Neuron 79:391-401, 2013

9. Czachowski CL, Chappell AM, Samson HH: Effects of raclopride in the nucleus accumbens on ethanol seeking and consumption. Alcohol Clin Exp Res 25:1431-1440, 2001

10. Dostrovsky JO, Lozano AM: Mechanisms of deep brain stimulation. Mov Disord 17 (Suppl 3):S63-S68, 2002

11. Everitt BJ, Robbins TW: Neural systems of reinforcement for drug addiction: from actions to habits to compulsion. Nat Neurosci 8:1481-1489, 2005

12. Gao G, Wang X, He S, Li W, Wang Q, Liang Q, et al: Clinical study for alleviating opiate drug psychological dependence by a method of ablating the nucleus accumbens with stereotactic surgery. Stereotact Funct Neurosurg 81:96-104, 2003

13. Ge S, Chang C, Adler JR, Zhao H, Chang X, Gao L, et al: Long-term changes in the personality and psychopathological profile of opiate addicts after nucleus accumbens ablative surgery are associated with treatment outcome. Stereotact Funct Neurosurg 91:30-44, 2013

14. Goodman WK, Foote KD, Greenberg BD, Ricciuti N, Bauer $\mathrm{R}$, Ward H, et al: Deep brain stimulation for intractable obsessive compulsive disorder: pilot study using a blinded, staggered-onset design. Biol Psychiatry 67:535-542, 2010

15. Grueter BA, Robison AJ, Neve RL, Nestler EJ, Malenka RC: $\Delta$ FosB differentially modulates nucleus accumbens direct and indirect pathway function. Proc Natl Acad Sci U S A 110:1923-1928, 2013

16. Hadar R, Vengeliene V, Barroeta Hlusicke E, Canals S, Noori HR, Wieske F, et al: Paradoxical augmented relapse in alcohol-dependent rats during deep-brain stimulation in the nucleus accumbens. Transl Psychiatry 6:e840-e840, 2016

17. Halpern CH, Tekriwal A, Santollo J, Keating JG, Wolf JA, Daniels D, et al: Amelioration of binge eating by nucleus accumbens shell deep brain stimulation in mice involves D2 receptor modulation. J Neurosci 33:7122-7129, 2013

18. Halpern CH, Torres N, Hurtig HI, Wolf JA, Stephen J, Oh MY, et al: Expanding applications of deep brain stimulation: a potential therapeutic role in obesity and addiction management. Acta Neurochir (Wien) 153:2293-2306, 2011

19. Halpern CH, Wolf JA, Bale TL, Stunkard AJ, Danish SF, Grossman M, et al: Deep brain stimulation in the treatment of obesity. J Neurosurg 109:625-634, 2008

20. Hammond C, Ammari R, Bioulac B, Garcia L: Latest view on the mechanism of action of deep brain stimulation. Mov Disord 23:2111-2121, 2008

21. Hansen S, Fahlke C, Hård E, Thomasson R: Effects of ibotenic acid lesions of the ventral striatum and the medial prefrontal cortex on ethanol consumption in the rat. Alcohol 12:397-402, 1995

22. Heinz A, Siessmeier T, Wrase J, Buchholz HG, Gründer G, Kumakura Y, et al: Correlation of alcohol craving with striatal dopamine synthesis capacity and D2/3 receptor availability: a combined $\left[{ }^{18} \mathrm{~F}\right] D O P A$ and $\left[{ }^{18} \mathrm{~F}\right] \mathrm{DMFP}$ PET study in detoxified alcoholic patients. Am J Psychiatry 162:1515-1520, 2005

23. Heinze HJ, Heldmann M, Voges J, Hinrichs H, Marco-Pallares J, Hopf JM, et al: Counteracting incentive sensitization in severe alcohol dependence using deep brain stimulation of the nucleus accumbens: clinical and basic science aspects. Front Hum Neurosci 3:22, 2009

24. Heldmann M, Berding G, Voges J, Bogerts B, Galazky I, Müller U, et al: Deep brain stimulation of nucleus accumbens region in alcoholism affects reward processing. PLoS One 7:e36572, 2012

25. Henderson MB, Green AI, Bradford PS, Chau DT, Roberts DW, Leiter JC: Deep brain stimulation of the nucleus accumbens reduces alcohol intake in alcohol-preferring rats. Neurosurg Focus 29(2):E12, 2010

26. Hingson R, Heeren T, Winter M, Wechsler H: Magnitude of alcohol-related mortality and morbidity among U.S. college students ages 18-24: changes from 1998 to 2001. Annu Rev Public Health 26:259-279, 2005

27. Huang Y, Mohan A, De Ridder D, Sunaert S, Vanneste S: The neural correlates of the unified percept of alcohol-related craving: a fMRI and EEG study. Sci Rep 8:923, 2018

28. Ihssen N, Cox WM, Wiggett A, Fadardi JS, Linden DEJ: Differentiating heavy from light drinkers by neural responses to visual alcohol cues and other motivational stimuli. Cereb Cortex 21:1408-1415, 2011

29. Imperato A, Mulas A, Di Chiara G: Nicotine preferentially stimulates dopamine release in the limbic system of freely moving rats. Eur J Pharmacol 132:337-338, 1986

30. Jasinska AJ, Stein EA, Kaiser J, Naumer MJ, Yalachkov Y: Factors modulating neural reactivity to drug cues in addiction: a survey of human neuroimaging studies. Neurosci Biobehav Rev 38:1-16, 2014

31. Juarez B, Morel C, Ku SM, Liu Y, Zhang H, Montgomery S, et al: Midbrain circuit regulation of individual alcohol drinking behaviors in mice. Nat Commun 8:2220, 2017

32. Kanaka TS, Balasubramaniam V: Stereotactic cingulumotomy for drug addiction. Appl Neurophysiol 41:86-92, 1978

33. Keistler CR, Hammarlund E, Barker JM, Bond CW, DiLeone RJ, Pittenger C, et al: Regulation of alcohol extinction and cue-induced reinstatement by specific projections among medial prefrontal cortex, nucleus accumbens, and basolateral amygdala. J Neurosci 37:4462-4471, 2017

34. Kellendonk C, Simpson EH, Polan HJ, Malleret G, Vronskaya S, Winiger V, et al: Transient and selective overexpression of dopamine D2 receptors in the striatum causes persistent abnormalities in prefrontal cortex functioning. Neuron 49:603-615, 2006

35. Knapp CM, Tozier L, Pak A, Ciraulo DA, Kornetsky C: Deep 
brain stimulation of the nucleus accumbens reduces ethanol consumption in rats. Pharmacol Biochem Behav 92:474479, 2009

36. Koob GF: Neurocircuitry of alcohol addiction: synthesis from animal models. Handb Clin Neurol 125:33-54, 2014

37. Koob GF: Theoretical frameworks and mechanistic aspects of alcohol addiction: alcohol addiction as a reward deficit disorder. Curr Top Behav Neurosci 13:3-30, 2013

38. Koob GF, Le Moal M: Drug abuse: hedonic homeostatic dysregulation. Science 278:52-58, 1997

39. Kuhn J, Gründler TOJ, Bauer R, Huff W, Fischer AG, Lenartz D, et al: Successful deep brain stimulation of the nucleus accumbens in severe alcohol dependence is associated with changed performance monitoring. Addict Biol 16:620-623, 2011

40. Kuhn J, Lenartz D, Huff W, Lee S, Koulousakis A, Klosterkoetter J, et al: Remission of alcohol dependency following deep brain stimulation of the nucleus accumbens: valuable therapeutic implications? J Neurol Neurosurg Psychiatry 78:1152-1153, 2007

41. Löf E, Olausson P, deBejczy A, Stomberg R, McIntosh JM, Taylor JR, et al: Nicotinic acetylcholine receptors in the ventral tegmental area mediate the dopamine activating and reinforcing properties of ethanol cues. Psychopharmacology (Berl) 195:333-343, 2007

42. Lüscher C, Malenka RC: Drug-evoked synaptic plasticity in addiction: from molecular changes to circuit remodeling. Neuron 69:650-663, 2011

43. Miller JW, Naimi TS, Brewer RD, Jones SE: Binge drinking and associated health risk behaviors among high school students. Pediatrics 119:76-85, 2007

44. Molander A, Söderpalm B: Glycine receptors regulate dopamine release in the rat nucleus accumbens. Alcohol Clin Exp Res 29:17-26, 2005

45. Morrell MJ, Halpern C: Responsive direct brain stimulation for epilepsy. Neurosurg Clin N Am 27:111-121, 2016

46. Müller UJ, Sturm V, Voges J, Heinze HJ, Galazky I, Büntjen L, et al: Nucleus accumbens deep brain stimulation for alcohol addiction-safety and clinical long-term results of a pilot trial. Pharmacopsychiatry 49:170-173, 2016

47. Müller UJ, Sturm V, Voges J, Heinze HJ, Galazky I, Heldmann M, et al: Successful treatment of chronic resistant alcoholism by deep brain stimulation of nucleus accumbens: first experience with three cases. Pharmacopsychiatry 42:288-291, 2009

48. Naimi TS, Brewer RD, Mokdad A, Denny C, Serdula MK, Marks JS: Binge drinking among US adults. JAMA 289:7075,2003

49. Nie H, Rewal M, Gill TM, Ron D, Janak PH: Extrasynaptic delta-containing $\mathrm{GABA}_{\mathrm{A}}$ receptors in the nucleus accumbens dorsomedial shell contribute to alcohol intake. Proc Natl Acad Sci U S A 108:4459-4464, 2011

50. Phillips TJ, Brown KJ, Burkhart-Kasch S, Wenger CD, Kelly MA, Rubinstein M, et al: Alcohol preference and sensitivity are markedly reduced in mice lacking dopamine D2 receptors. Nat Neurosci 1:610-615, 1998

51. Poznyak V, Rekve D (eds): Global Status Report on Alcohol and Health 2014. Geneva: World Health Organization, 2014 (http://www.who.int/substance_abuse/publications/ global_alcohol_report/en/) [Accessed June 5, 2018]

52. Quarfordt SD, Kalmus GW, Myers RD: Ethanol drinking following 6-OHDA lesions of nucleus accumbens and tuberculum olfactorium of the rat. Alcohol 8:211-217, 1991

53. Ramchandani VA, Umhau J, Pavon FJ, Ruiz-Velasco V, Margas W, Sun H, et al: A genetic determinant of the striatal dopamine response to alcohol in men. Mol Psychiatry 16:809-817, 2011

54. Rewal M, Jurd R, Gill TM, He DY, Ron D, Janak PH: $\alpha 4$ containing $\mathrm{GABA}_{\mathrm{A}}$ receptors in the nucleus accumbens mediate moderate intake of alcohol. J Neurosci 29:543-549, 2009

55. Rezai AR, Krishna V, Bogner J, Kramer D, Needleman B, Emerson AM, et al: Feasibility of nucleus accumbens deep brain stimulation for morbid, treatment-refractory obesity. Neurosurgery 82:E136-E137, 2018 (Letter)

56. Rhodes JS, Best K, Belknap JK, Finn DA, Crabbe JC: Evaluation of a simple model of ethanol drinking to intoxication in C57BL/6J mice. Physiol Behav 84:53-63, 2005

57. Sacks JJ, Gonzales KR, Bouchery EE, Tomedi LE, Brewer RD: 2010 national and state costs of excessive alcohol consumption. Am J Prev Med 49:e73-e79, 2015

58. Schacht JP, Anton RF, Myrick H: Functional neuroimaging studies of alcohol cue reactivity: a quantitative meta-analysis and systematic review. Addict Biol 18:121-133, 2013

59. Simms JA, Steensland P, Medina B, Abernathy KE, Chandler LJ, Wise R, et al: Intermittent access to $20 \%$ ethanol induces high ethanol consumption in Long-Evans and Wistar rats. Alcohol Clin Exp Res 32:1816-1823, 2008

60. Smith CT, Wallace DL, Dang LC, Aarts E, Jagust WJ, D'Esposito M, et al: Modulation of impulsivity and reward sensitivity in intertemporal choice by striatal and midbrain dopamine synthesis in healthy adults. J Neurophysiol 115:1146-1156, 2016

61. Spanagel R, Hölter SM, Allingham K, Landgraf R, Zieglgänsberger W: Acamprosate and alcohol: I. Effects on alcohol intake following alcohol deprivation in the rat. Eur J Pharmacol 305:39-44, 1996

62. Sturm V, Lenartz D, Koulousakis A, Treuer H, Herholz K, Klein JC, et al: The nucleus accumbens: a target for deep brain stimulation in obsessive-compulsive- and anxietydisorders. J Chem Neuroanat 26:293-299, 2003

63. Taverna S, van Dongen YC, Groenewegen HJ, Pennartz CMA: Direct physiological evidence for synaptic connectivity between medium-sized spiny neurons in rat nucleus accumbens in situ. J Neurophysiol 91:1111-1121, 2004

64. Thavorncharoensap M, Teerawattananon Y, Yothasamut J, Lertpitakpong C, Chaikledkaew U: The economic impact of alcohol consumption: a systematic review. Subst Abuse Treat Prev Policy 4:20, 2009

65. Urban NBL, Kegeles LS, Slifstein M, Xu X, Martinez D, Sakr E, et al: Sex differences in striatal dopamine release in young adults after oral alcohol challenge: a positron emission tomography imaging study with $\left[{ }^{11} \mathrm{C}\right]$ raclopride. Biol Psychiatry 68:689-696, 2010

66. Urbano F, Leznik E, Llinás R: Cortical activation patterns evoked by afferent axons stimuli at different frequencies: an in vitro voltage-sensitive dye imaging study. Thalamus Relat Syst 1:371-378, 2002

67. Voges J, Müller U, Bogerts B, Münte T, Heinze HJ: Deep brain stimulation surgery for alcohol addiction. World Neurosurg 80:28.e21-28.e31, 2013

68. Wilden JA, Qing KY, Hauser SR, McBride WJ, Irazoqui PP, Rodd ZA: Reduced ethanol consumption by alcohol-preferring $(\mathrm{P})$ rats following pharmacological silencing and deep brain stimulation of the nucleus accumbens shell. J Neurosurg 120:997-1005, 2014

69. Wrase J, Kahnt T, Schlagenhauf F, Beck A, Cohen MX, Knutson B, et al: Different neural systems adjust motor behavior in response to reward and punishment. Neuroimage 36:1253-1262, 2007

70. Wu H, Miller KJ, Blumenfeld Z, Williams NR, Ravikumar VK, Lee KE, et al: Closing the loop on impulsivity via nucleus accumbens delta-band activity in mice and man. Proc Natl Acad Sci U S A 115:192-197, 2018

71. Xia Y, Driscoll JR, Wilbrecht L, Margolis EB, Fields HL, Hjelmstad GO: Nucleus accumbens medium spiny neurons target non-dopaminergic neurons in the ventral tegmental area. J Neurosci 31:7811-7816, 2011 
72. Yang H, de Jong JW, Tak Y, Peck J, Bateup HS, Lammel S: Nucleus accumbens subnuclei regulate motivated behavior via direct inhibition and disinhibition of VTA dopamine subpopulations. Neuron 97:434-449.e4, 2018

73. Yen CP, Kuan CY, Sheehan J, Kung SS, Wang CC, Liu CK, et al: Impact of bilateral anterior cingulotomy on neurocognitive function in patients with intractable pain. J Clin Neurosci 16:214-219, 2009

\section{Disclosures}

The authors report no conflict of interest concerning the materials or methods used in this study or the findings specified in this paper.

\section{Author Contributions}

Conception and design: Halpern, Ho, Giardino. Acquisition of data: Ho, Salib. Analysis and interpretation of data: Halpern, Ho, Salib. Drafting the article: Ho, Salib. Critically revising the article: Halpern, Ho, Pendharkar, Sussman, Giardino. Reviewed submitted version of manuscript: all authors. Administrative/technical/material support: Halpern, Pendharkar, Sussman, Giardino. Study supervision: Halpern, Giardino.

\section{Correspondence}

Casey H. Halpern: Stanford University School of Medicine, Stanford,CA. chalpern@stanford.edu. 